\title{
Applying Moral Foundations Theory to Understanding Public Views of Sexual Offending
}

\author{
Craig A. Harper* \\ University of Lincoln (UK) \\ Andrew J. Harris \\ University of Massachusetts Lowell (USA)
}

*Correspondence concerning this article should be addressed to Craig Harper, School of Psychology, University of Lincoln, Brayford Pool, Lincoln, LN6 7TS, UK (email:

craigaharper19@gmail.com)

This version was accepted for publication in the Journal of Sexual Aggression, and may differ slightly from the version that appears in print. For the most recent version, please see:

Harper, C. A., \& Harris, A. J. (2016). Applying moral foundations theory to understanding public views of sexual offending. Journal of Sexual Aggression. doi: 10.1080/13552600.2016.1217086. 


\begin{abstract}
Much research has examined the views held by citizens about sexual offenders and related policy responses. Although studies have extensively examined demographic correlates of such views, little attention has been paid to psychological mechanisms that underpin them. Gaining a deeper understanding of such mechanisms may ultimately prove useful for informing communication strategies around the problem of sexual violence. We propose the application of moral foundations theory (MFT) as a means of exploring the roots of the current punitive consensus around sexual crime policy at the macro level, as well as individual variability in attitudes about sexual violence. Following an overview of the sexual offender policy landscape, and a description of MFT principles, we outline how this framework can help to explain both convergence and divergence in responses to sexual offending among members of the public. We also provide a series of testable hypotheses to stimulate further research in this area.
\end{abstract}

Keywords: moral foundations theory, sexual offending, social discourse, political communication, social policy 


\section{Applying Moral Foundations Theory to Understanding Public Views of Sexual \\ Offending}

Over recent decades, converging discourses from various streams of social policy have led to a generalized hardening of the tone around sexual crime policy in contemporary societies (for a review, see Bonnar-Kidd, 2010). The elevation of sexual crime as a key public policy issue since the latter part of the twentieth century has produced a range of social and justice system responses to sexual offending behavior, along with high levels of public support for these responses despite mixed findings regarding policy efficacy (Kernsmith, Craun, \& Foster, 2009; Levenson, Brannon, Fortney, \& Baker, 2007). Although previous literature has examined demographic and other correlates of public support for prevailing sexual offender management policies, there has been little research focus on the underlying psychological factors contributing to these levels of policy support (Anonymous, under review).

This article aims to anchor the social discourse around sexual crime within Haidt and Graham's (2007) moral foundations theory (MFT). We begin by providing an explication of the differences between punitive and progressive responses to sexual crime, followed by an explanation of core MFT principles and a critical application of MFT to prevailing social discourse around sexual crime and its perpetrators. The article concludes with an agenda for research in this area, such as to empirically examine policy and media discourses around sexual crime using an approach that is consistent with the tenets of MFT.

\section{Punitive and Progressive Approaches to Sexual Offender Policy: Two Schools of}

\section{Thought}

Broadly speaking, policy responses directed at perpetrators of sexual crime may be viewed along a continuum from policies that emphasize punishment (punitivism) and those 
that emphasize reform and social reintegration (progressivism). Punitivism emphasizes the detection and apprehension of sexual offenders after they commit their offenses, and subjecting these individuals to harsh punishments and potentially lifelong restrictions on their liberty after conviction. In contrast, a progressive model emphasizes the principles of prevention and social reintegration of offenders, generally informed by the application of empirical evidence. Those endorsing progressive responses to sexual crime emphasize interventions focused both on populations who may be at risk of committing an offense, as well as engagement with those who have prior sexual offense convictions as a means of facilitating long-term desistance.

\section{Punitive Responses to Sexual Offending}

In the United States, public policies directed at control and punishment of sexual offenders date to the first half of the $20^{\text {th }}$ century. Between the 1930 s and the 1960 s, many states adopted so-called "sexual psychopath" laws that provided for the indefinite psychiatric commitment of individuals deemed to pose a risk to society, including those designated as "sexual degenerates" or "sex fiends" (Sutherland, 1950; Jenkins, 1998). State and local laws requiring the registration of sexual offenders with law enforcement authorities, which have since become a central element of U.S. sexual offender management strategies, date back to the 1940s (Logan, 2009).

Although these precursor policies fell into gradual disuse beginning in the 1960s, they (along with a range of other punishment and control-oriented policies) re-emerged in the U.S. beginning in the early 1990s. At the forefront of this movement was Washington's Community Protection Act (CPA) of 1990 - a piece of legislation that would set the stage for many key facets of contemporary sexual offender policies in the United States and elsewhere. Motivated by a series of high-profile sexual offenses that seized the public's attention, the 
CPA established longer and less flexible sentences for sexual offenders, set forth the nation's first laws providing for notifying citizens about sexual offenders living in the community, and re-established the practice of post-prison commitment of sexual predators via civil proceedings (Boerner, 1992).

Following Washington's lead, many state legislatures across the U.S. enacted new sexual predator civil commitment statutes over the ensuing years, with the federal government passing its own civil commitment law in 2006 (Harris, 2009). Additionally, the CPA's community notification provisions foreshadowed a dramatic expansion of sexual offender registration systems across the U.S., and the attendant emergence of "Megan's Laws" providing for public access to registry information. While initially emanating from the individual states, the expansion of sexual offender registration and notification (SORN) systems in the U.S. was promoted and accelerated largely through national laws enacted by the U.S. Congress, beginning with the Jacob Wetterling Crimes Against Children Act (1994) and extending through the passage and implementation of the Adam Walsh Child Protection and Safety Act (2006). Through a convergence of state and federal action, all U.S. states and territories operate publicly-accessible internet sex offender websites, and the nation's sex offender registries contained information on over 843,000 individuals as of December 2015 (National Center for Missing and Exploited Children, 2015).

Coupled with the expansion of SORN systems, U.S. states have passed a range of additional laws directed toward control and restriction of sex offenders and their activities. Prominent among these have been "Jessica's Laws" that set forth longer sentences and mandatory lifetime supervision and GPS monitoring for certain offenders; residence restriction laws that prohibit registered sex offenders from living near schools or other places where children might congregate; and restrictions on internet or social media use. 
Such policy measures are not limited to the United States. Sexual offenders in the U.K. are also subject to registration procedures, pursuant to the 2003 development of the Violent and Sex Offenders Register (ViSOR) and the subsequent adoption of a public disclosure scheme in 2010. These policies stemmed in part from the 2000 abduction and murder of nineyear-old Sarah Payne by a previously convicted pedophile, which sparked a national outrage about how many people with sexual convictions for crimes perpetrated against children were living unknown within local communities. One national newspaper (now defunct following a national scandal about press ethics) launched a campaign to introduce 'Sarah's Law', which would allow parents and members of local communities to access information about the sexual offending history of people about whom they have concerns. In a controversial move, this publication printed the names and addresses of convicted pedophiles in order to highlight the apparent scale of this practice of allowing people with these kinds of convictions to live in the community. The front page headline was direct in its tone:

"There are 110,000 child sex offenders in Britain.. one for every square mile. The murder of Sarah Payne has proved police monitoring of these perverts is not enough. So we are revealing WHO they are and WHERE they are.. starting today" (News of the World, $23^{\text {rd }}$ July 2000, p. 1).

This campaign for Sarah's Law was initially rejected by the Labour Government of Tony Blair. However, upon increased public pressure a pilot study was initiated in 2008 (Kemshall \& Wood, 2010). After reading the evaluation report, the newly elected Conservative Government announced in August 2010 that the Child Sex Offender Disclosure Scheme (CSODS) would be enacted and implemented nationwide. This scheme allows members of the public to apply for information about the potential sexual offending histories of people about whom they have concerns in their local communities. After conducting various searches and risk assessments, a decision about whether to disclose information about 
the individual under examination is made. If a disclosure of information is deemed necessary, this can be made either to the applicant, or to a person better placed to protect local children. The recipients of such information are bound by a confidentiality agreement to not share any information that is disclosed.

\section{Progressive Responses to Sexual Offending}

In contrast with punitive responses to sexual crime, progressive initiatives aim to reduce the incidence of sexual (re)offending by working constructively and therapeutically with those at risk of perpetrating such crimes. For example, the German Project Prevention Dunkelfeld (from here, 'the Dunkelfeld Project'; Beier et al., 2009, 2016) offers anonymous therapy to people who self-identify as having pedophilic sexual interests. The Dunkelfeld Project aims to offer early intervention (via psychological and psychiatric treatment) in an attempt to prevent child sexual abuse before it occurs. Early evidence of the effectiveness of the Dunkelfeld Project comes from small-scale studies of the interventions that are offered, with data indicating reductions in the expression of offense-supportive cognitions (Amelung, Kuhle, Konrad, Pauls, \& Beier, 2012), and improved sexual self-regulation (Beier et al., 2015).

Another example of progressive interventions is Circles of Support and Accountability (CoSA), which engages people with convictions for sexual offenses ('core members') through the provision of practical and pastoral support as a means of reducing re-offense risk. Support is provided by a small number of community-based volunteers (the 'inner-circle'), who in turn are supported by trained professionals (the 'outer-circle'). The role of the innercircle is to meet regularly with the core member, and to provide them with practical (e.g., facilitate access to medical help, employment opportunities, and stable housing) and emotional support as they work towards long-term desistance. This approach is consistent 
with the Integrated Theory of Desistance from Sexual Offending (ITDSO; Göbbels, Ward, \& Willis, 2012), in that a rehabilitation-facilitating environment is carried forward from prison and into the community (Kitson-Boyce, Blagden, Elliott, Winder, \& Dillon, 2015). Evaluations of CoSA in reducing reoffending rates appears promising, with a 70-83\% reduction in sexual reoffending being reported when core members' trajectories are compared with risk assessments and matched controls (Wilson, Cortoni, \& McWhinnie, 2009).

\section{Public Support for Sexual Offender Policies}

Surveys of the public have indicated high levels of citizen support for sexual offender policies at the punitive end of the spectrum, and generally lower levels of support for progressively-oriented approaches (e.g., Levenson et al., 2007; Mears, Mancini, Gertz, \& Bratton, 2008). Studies in the U.S., U.K., and elsewhere suggest that this high level of support for punitively-oriented policies has been coupled with the widespread adherence to misconceptions about sexual offenders, including beliefs that sexual offenders are most commonly strangers to their victims, collectively at high risk of re-offending, and highly resistant to rehabilitation (Brown, Deakin, \& Spencer, 2008; Craun \& Theriot, 2009; KatzSchiavonne, Levenson, \& Ackerman, 2008; Levenson et al., 2007).

Explaining the high levels of public support for punitive sex offender policies, some have attributed such attitudes and beliefs to an erroneous tendency among citizens, the media, and policymakers to think of sexual offenders as a homogenous group (Galeste, Fradella, \& Vogel, 2012; Levenson et al., 2007; Sample \& Bray, 2006). Harris and Socia (2014) suggested that this assumed homogeneity of the sex offender population has also permeated much public opinion survey research, noting that:

"Prompts such as "What percentage of sex offenders do you think commit new sexual crimes after their release from prison?" or "Do you think that the names and addresses 
of convicted sex offenders should be made available to the public?" implicitly force respondents to make general inferences and statements about a knowingly diverse population. Ultimately, it may be that the resulting research tells us more about respondents' visceral reactions to the "sex offender" label than it does about rational assessments regarding adults or youth who have perpetrated sexual offenses". (Harris \& Socia, 2014, p. 2)

To this general point, surveys that have prompted respondents to look beyond generalizations and to differentiate among various sexual offending scenarios, have found that levels of support for punitive measures may vary considerably based on situational, perpetrator, and victim characteristics. For example, Kernsmith et al., (2009) found that citizen beliefs about the appropriateness of subjecting an offender to community notification varied based on offense scenario. For example, $97 \%$ of respondents supported this procedure for adults who sexually abuse children, but only $65 \%$ found it suitable for a statutory rape case involving a 21-year-old perpetrator and a 16-year-old victim. In another study, Mears et al. (2008) found variation in respondent beliefs about prison sentences for sex offenders, with $97 \%$ supporting incarceration for sexual assault of a minor, $80 \%$ for indecent exposure to a child, and $46 \%$ for indecent exposure to an adult. Such findings suggest that, although the public may be fairly unified in its support of punitive measures for certain types of sexual offenders (for example, pedophiles who victimize young children), punitive views may be tempered when respondents are prompted to consider the broader range of behaviors that might be subsumed under the "sexual offender" designation (King \& Roberts, 2015; Salerno et al., 2010).

There are likely considerable differences within the general population regarding perceptions about the egregiousness of certain offending behaviors, the culpability of offenders, and the appropriateness of various sanctions. While some of these differences may be correlated with demographic factors such as age, race, or level of education (Anonymous, under review), there are also likely to be significant psychological factors at work that can 
explain divergent levels of punitive attitudes among the general public. One such series of factors that is likely to be implicated in how people view societal responses to sexual crimes are those related to the composition of moral belief systems.

\section{Moral Foundations Theory}

Moral foundations theory (MFT) offers a theoretical framework to understand and explore such psychological dynamics. Based on work done in the fields of cultural anthropology and evolutionary psychology, MFT views human morality as a multidimensional construct stemming from intuitive processes (Haidt, 2012). The principles of MFT may be described on the basis of three main premises: (1) that implicit moral judgments precede rational decision-making; (2) that morality is a multi-dimensional construct; and (3) that the relative weight given to various moral dimensions is variable across the population.

\section{Premise 1: Feel First, Rationalize Later}

Haidt (2012) uses a metaphor for the mind involving an elephant (analogous to intuition) and its rider (analogous to conscious reasoning), and argues that, in moral reasoning, the rider is a servant of the elephant. This reflects a now commonly-held view in the psychology of communication, that explicitly-reasoned judgments are rationalizations of decisions that are initially made by automatic and intuitive processes (for a review of this literature, see Kahneman, 2012). This argument is consistent with the ideas put forward by dual-process models of human cognition, which distinguish between what Kahneman (2012) has referred to as the primitive "system one" (through which we make a majority of daily decisions and judgments based on unconscious heuristic-driven processes), and the more evolutionarily advanced "system two" (through which we make deliberative rational decisions based on processing of information). Within the context of MFT, the "system one" 
heuristic processes of interest are those related to deeply embedded notions of "right" and "wrong" that are based on moral belief systems. As argued by scholars such as Sternberg (1984) and Dweck, Chui, and Hong (1995), 'system one' thinking may be driven by implicit (i.e., non-conscious) core beliefs about the world. As highlighted through MFT, such automatic implicit processes may also be relevant when thinking about the development of people's moral opinions.

\section{Premise 2: Morality as a Multi-Dimensional Construct}

In their earlier work that established the groundwork for MFT, Haidt and Joseph (2004) identified four 'intuitive ethics' that form the basis for human morality across cultures preventing suffering, hierarchy, reciprocity, and purity. In the ensuing years, six foundations have been identified, which are postulated as making up the "moral mind" (Haidt, 2012).

The care foundation refers to our human instinct to protect others from harm. This foundation is particularly pronounced when applied to our need to protect those who are perceived as vulnerable, particularly children. Although perhaps the more universally shared dimensions of morality across cultures and across the ideological spectrum, the care foundation carries significantly greater weight among those with a more liberal political orientation, who tend to place less value on other moral foundations than those at the conservative end of the spectrum.

The fairness foundation refers to the human construction of "right" and "wrong" associated with one's adherence to the rules of society - it is the part of our moral makeup that involves distinguishing between those who "play by the rules" and those who are perceived as cheating or claiming more than they deserve. In the realm of distribution of resources and opportunity within society, liberals view fairness as a function of equality of opportunity without the hindrance of systemic barriers (e.g., racism, or sexism), while 
conservatives view fairness as a function of proportionality, deserved outcomes being judged on the basis of people's initial behaviors.

The loyalty foundation stems from our evolutionary need for tribal connection and cohesion, and the associated instinct to identify and support those in our family, community, and nation. In the domain of political and social discourse, Haidt (2012) argued that the loyalty foundation "binds and blinds". That is, it may serve to unite individuals through expressions of patriotism, and may also lead to animosity and misunderstanding directed at those who are perceived as belonging to 'out-groups'.

The authority foundation is linked to the evolutionary demand for social hierarchies as a means of maintaining order. In the family microcosm, this moral foundation is manifested in respect for one's parents or, in some cultural contexts, respect for gender roles within the family (Lakoff, 2014). In a societal context, this foundation is implicated in one's deference and respect for authority figures such as teachers, work supervisors, and police officers.

The purity foundation corresponds to our evolutionary need to avoid things that are noxious, unnatural, or pathogenic. This foundation is closely linked to the instinct of disgust, which in some cases may serve an adaptive purpose (e.g., avoiding of rancid-smelling food that may make us sick). In contemporary society, however, this foundation has permeated into the social realm, reflected in moral beliefs about "social pathogens" that may upset societal order. In this respect, the purity foundation may be evoked in attitudes toward issues such as homosexuality and gay marriage.

The liberty foundation is based on the notion that people should be free from control by tyrants or other external agents. While the liberty foundation is somewhat less empirically developed than the other five foundations, there is a strong basis to suggest that resistance to oppression (and attributions of amorality to the oppressors) is viewed as an important element of morality across certain segments of society. 'Social liberty' refers to freedom from 
interference in lifestyle matters, while 'economic liberty' refers to the freedom to keep and spend earned monies in any way one chooses. In a political context, the liberty foundation is most closely manifested in the doctrine of the libertarian movement.

\section{Premise 3: Views of 'Morality' Vary across Groups and Individuals}

As suggested above, studies have found significant inter-group differences in the relative weight assigned to the various moral foundations, as well as differences in the ways that these foundations are defined. Haidt (2008) used the analogy of an audio equalizer as a metaphor for morality, with each of the moral foundations acting as an independent 'channel', which is 'tuned' by the individual as a result of their experience with the external world. The resultant composition of moral foundations leads to an ideographic ideological orientation for that person. While the majority of studies in MFT research are based on data collected from American samples, Haidt (2008) suggested that the trends in these data are also present in other samples from Western and Eastern Europe, the Middle East, Southern and Eastern Asia, and Australia and New Zealand. Nevertheless, care should be taken when extrapolating these findings to vastly different cultures.

Within the MFT literature, political ideology has served as the critical source of distinction related to moral foundations, with studies consistently suggesting that selfidentified liberals and conservatives endorse each of the six moral foundations to varying degrees (Haidt, 2012; Haidt \& Graham, 2007; Iyer, Koleva, Graham, Ditto, \& Haidt, 2012).

On the initial five moral foundations, Haidt (2012) suggested that self-identified liberals typically endorse a 'two-channel' conceptualization of morality, and value issues around 'care and harm' and 'fairness' (so-called 'individualizing foundations') above all others. In contrast, conservatives endorse all five of Haidt and Graham's (2007) initial five moral foundations more-or-less equally, with a particular emphasis on loyalty, authority, and 
purity (so-called 'binding foundations'). In this sense, liberals stress the importance of acting fairly towards socially-disadvantaged groups, and protecting the most vulnerable in society from harm. Conservatives, whilst still taking the needs of these disadvantaged groups into account, also advocate obedience to authority, patriotism, and social behaviors adhering to the purity foundation.

Libertarians, in contrast to liberals and conservatives, tend to place comparatively lower emphasis on the initial five moral foundations, and more emphasis on notions of social and economic liberty (Iyer et al., 2012). Consistent with social stereotypes, political liberals score high in relation to social liberty, while conservatives score high on indices of economic liberty. Thus, Iyer et al. concluded that libertarians have a 'one-foundation' view of morality, and can choose to side with either liberal or conservative groups depending on the specific issue being debated.

\section{Applying MFT to Sexual Offender Policy Discourse: Theoretical and Research}

\section{Suggestions}

Generally, punitive attitudes about crime are consistent with a conservative ideological orientation, as people who commit criminal offenses are guilty of transgressing the 'binding foundations' of morality that contribute to a healthy functioning society (Graham, Haidt, \& Nosek, 2009). In contrast, liberals are said to be more likely to support more rehabilitative policies because of an ideological desire to view offenders as being able to change their behavior (Skitka, Mullen, Griffin, Hutchinson, \& Chamberlin, 2002). This conservative/liberal distinction, however, does not appear to be so clear in relation to responses to sexual offending. That is, these groups have been found to both endorse broadly similar levels of support for punitive measures directed at sexual offenders (Mears et.al, 2008; Olver \& Barlow, 2010). 
Yet as previously described, a closer look suggests that there may be critical differences in terms of how sexual offenses and offenders are viewed across the population. Not only may members of the public follow variable 'moral pathways' to arrive at seemingly compatible policy positions, but there is a sound basis to believe that people's moral compositions (as operationalized by MFT) may have an impact on their levels of support for punitive measures in response to various types of sexual offending behaviors. By applying the principles of MFT to examinations of public opinion surrounding sexual crimes and sexual offender policy, we may gain a more nuanced view of this phenomenon, helping to inform policy discourse and communication strategies.

\section{'Feeling First' about Sexual Offending}

Violations of moral and legal norms tend to be met with visceral responses, such as disgust, fear, and anger. This response style is often conceptualized as moral outrage (Bastian, Denson, \& Haslam, 2013), with a number of researchers arguing that this response is, in part, responsible for people's negative judgments about sexual offenders (Salerno et al., 2010; Vess, 2009; Willis et al., 2010). These reactions occur non-consciously. As such, the moral outrage response to sexual offending is consistent with the first principle of MFT people feel a response before they deliberatively consider the issue. Thus, we argue that policy discourses around the issue of sexual offending are permeated with emotion.

The visceral nature of public responses to sexual offending is reflected by a number of recent studies demonstrating the power of language and labels in influencing punitive attitudes. As suggested earlier, Harris and Socia (2014) found that survey respondents asked about their support for community notification, residence restrictions, and social network bans for "sex offenders" demonstrated significantly higher levels of support for these policies than a matched group that was given a similar series of prompts using the more sanitized 
"people who have committed sexual offenses". They also found higher levels of support for requiring "juvenile sex offenders" to register with police, compared to "minor youth who have committed sexual offenses".

Similarly, Imhoff (2015) found that people expressed more punitive attitudes (operationalized as support for preventative incarceration and notification procedures) when people were described as "pedophiles" than when presented with the alternative label of “people with a sexual interest in [prepubescent] children”. The pedophile label was also associated with greater judgments of controllability, meaning that "pedophiles" were viewed as being more responsible for their sexual urges than people described with the more neutral label. In a separate study, up to a third of participants in a U.S.-based sample (or one-fifth in a sample tested in Germany) suggested that pedophiles would be better off dead than continuing to live with their deviant sexual interests (Jahnke, Imhoff, \& Hoyer, 2015). In each of these samples, participants were explicitly told that they should think about pedophiles who had not been convicted of a sexual offense. Thus, these findings suggest that labeling an individual as a "pedophile" (or a "sex offender") evokes a visceral reaction that is independent of a rational understanding of that individual's offending behavior.

\section{Using Moral Foundations to Explore Public Views towards Sexual Offending}

As previously outlined, MFT views morality as a multi-dimensional construct. As such, each of the moral foundations may be implicated in some way in explaining how and why people come to make decisions about the issue of sexual offending. Here, we outline how these foundations may play a role in mediating such responses. Within these analyses, a number of testable hypotheses emerge, with these forming the basis of a potential agenda for future research. 
Care foundation. The care foundation is based on the widely-held moral instinct to protect others from harm, particularly those in society who are deemed most vulnerable. Consistent with this, the history of sexual offender policies (dating back to the early $20^{\text {th }}$ century), is permeated with an implicit intention of protecting vulnerable groups particularly women and children - from abuse and exploitation (Lobanov-Rostovsky \& Harris, 2012).

In a general sense, this 'care foundation instinct' is not entirely misplaced. That is, women and children overwhelmingly represent the majority of reported victims of sexual crime (Office for National Statistics, 2015; Truman \& Langton, 2015). At the same time, however, notions of innocence and vulnerability (and, in turn the conditions under which the care/harm instinct is triggered) will vary considerably across individuals and groups. Certainly, one would expect punitive attitudes toward sex offenders to be most convergent and pronounced in cases where victim innocence and vulnerability is most commonly accepted. Examples of these include offenses involving young children who are randomly targeted for sexual abuse or exploitation. However, we would hypothesize that the activation of the care instinct - and in turn levels of punitive attitude convergence among the public - is likely to be considerably more variable in other situational scenarios (e.g., in cases involving teenage or adult victims, or those in which the victim might be viewed to have been complicit in the offending behavior). Such mechanics may be implicated, for example, in the "victim blaming' that often occurs in cases of reported sexual violence and abuse, and in societal attitudes and responses to cases involving non-stereotypical perpetrators or victims.

As noted earlier, responses to sexual offending are typically more negative and punitive when people consider 'sexual offenders' in a general sense than when contemplating individual scenarios. Given that the care foundation is ascribed to extensively within the population, this may explain much of the broad-based punitive consensus directed toward 
"sex offenders" as a collective entity. From an empirical standpoint, however, it is important to shift the locus of inquiry toward a more nuanced view that accounts for the significant variability within the sexual offender population. Thus, our focus should be less driven by the question of whether the care foundation is implicated in peoples' judgments about sexual offenders (it most surely is), but rather how, and under what conditions, this foundation is evoked.

Fairness foundation. As discussed earlier, the fairness foundation encompasses ideas of justice, rights, and individual autonomy. Although in its earlier iterations, MFT emphasized the theme of social equality (a liberal conceptualization) as central to notions of fairness, more recent constructions emphasize the idea of proportionality (a more conservative notion). Viewed in the latter context, one would hypothesize that those whose moral inclinations are strongly dominated by notions of fairness (in comparison to other moral dimensions) would be inclined to adjust their punitive responses to sexual offending based on both the perceived harmfulness of the offending behavior, and on the perceived responsibility of the perpetrator, as these constructs relate to concepts embodied in the proportionality aspect of the fairness foundation. For example, one might expect the fairness foundation to be a moderating factor in the endorsement of punitive responses to a first-time juvenile offender compared to an adult repeat offender.

The fairness foundation may also be implicated in other ways. In line with a more liberal conceptualization, the fairness foundation also encompasses notions of social equality and equity of opportunity. Such views may be closely aligned with feminist conceptualizations of rape and other forms of violence against women, which frame sexual violence as a manifestation of gender-based oppression (Brownmiller, 1975). Viewed in this context, one might hypothesize that individuals ascribing to such notions of fairness might 
express higher levels of punitive attitudes in cases involving crimes that are perceived as strongly misogynistic, or offenses that are otherwise seen as reflecting male social dominance (e.g., spousal rape).

Loyalty foundation. The loyalty foundation stresses the value of tribal bonds with one's family, nation, or community of interest. Of particular relevance for the current analysis, the loyalty foundation is predicated on a distinction between 'us' and 'them' - a distinction that is clearly manifested in attitudes and responses to sexual offenders. As such, we would hypothesize that those who strongly endorse the loyalty foundation would express a greater support for uniformly punitive policies that create social distance between sexual offenders and the community (e.g., incarceration and registration), rather than more progressive policies (e.g., CoSA) that aim to successfully reintegrate sexual offenders back into the community.

As discussed earlier, Haidt (2012) noted that "morality binds and blinds". This is a principle that is starkly manifested in the case of the loyalty foundation. Applied to the problem of sexual violence and abuse, this idea offers a framework through which to understand the propensity of many citizens to overestimate the extent of 'stranger danger' (which relegates sexual offenders to the status of an 'out-group'), and underestimate risk of sexual abuse that may occur within the home or in trusted community circles (an idea that requires a recognition that many sexual offenders may be part of one's 'in-group'). This phenomenon may be seen in many cases within recent memory, including the resistance of many members of the Catholic Church to accept and address systemic patterns of sexual abuse over many decades, and multiple instances in which systems and institutions have 'closed ranks' around sexual abuse committed by their valued members, such as in the U.S. case of Pennsylvania State University's football coach Jerry Sandusky (who was eventually 
convicted on 45 counts, and sentenced to 60 years imprisonment, relating to the grooming and sexual abuse of children after more than a decade of cover-ups at Penn State).

Adherence to the loyalty foundation may also be complicit in responses to intra-familial sexual abuse, and may explain the tendency for such cases to be under-reported in the interests of maintaining family unity. Accordingly, one would hypothesize that high levels of adherence to the loyalty foundation may be associated with a greater tendency to minimize and/or deny the presence of sexual violence and abuse within one's immediate social or familial groups.

Authority foundation. The authority foundation places paramount value on respect for both the rule of law and established social hierarchies. Regarding the rule of law, sexual offending is judged as immoral in the authority domain strictly on the basis that it violates the rules that society has established, and that the criminal justice system is charged to enforce. As such, those who adhere more closely to this foundation would be expected to express significantly more pronounced punitive attitudes for any individuals who commit a sexual crime, independent of their assessment of that crime's seriousness. ${ }^{1}$

Regarding respect for social hierarchies, the authority foundation may be implicated in public attitudes toward rape and violence against women, particularly when coupled with conservative views of males as dominant to females in the social hierarchy (Lakoff, 2014). In line with this, we might hypothesize that those adhering to traditional notions of authority would be more likely to minimize (and endorse less punitive responses to) many forms of rape, such as 'date rape' or cases occurring within marriages.

\footnotetext{
${ }^{1}$ This is not to suggest that such individuals would endorse a uniformly punitive response to all sexual crimes, but rather that such a sense of proportionality would come from other moral foundations (e.g., fairness) that are independent of their views on authority.
} 
Also, consistent with Haidt's adage that "morality binds and blinds", the authority foundation may also exert its influence in tandem with the loyalty foundation to serve as a barrier to recognizing and addressing sexual violence and abuse committed by those in positions of authority. Examples of where these behaviors may be prevalent include sexual abuse committed within the military, or acts of sexual abuse perpetrated by community religious leaders. As such, we may expect that those who endorse the authority foundation may minimize the legitimacy of claims around institutional abuse in these contexts, or deny their existence altogether.

Purity foundation. The purity foundation refers to that portion of moral judgments stemming from our innate aversion to phenomena (including perceived 'social pathogens') that are deemed to be disgusting and/or unnatural. It should come as little surprise that matters involving sexual behaviours prominently intersect with notions of purity. For instance, Gray and Keeney (2015) found that participants overwhelmingly provided sexual examples when asked to describe scenarios that depict impurity. Examples of the most commonly provided scenarios included child molestation and rape - two of the most commonly reported categories of sexual crime within the mainstream media (Harper \& Hogue, 2014).

In an analysis of the link between disgust sensitivity and views about sexual purity, Adams, Stewart, and Blanchar (2014) found that participants who were exposed to a foul odor rated gay marriage, premarital sexual relations, and the use of pornography as more immoral than participants who were not exposed to such a smell. Several studies have found that fictitious cases of consensual incest evoke strong disgust reactions, even when participants are given supplementary information suggesting that there was no chance of 
conception and that no emotional harm would come from the incestuous encounter (GinerSorolla \& Russell, 2009; Haidt, Koller, \& Dias, 1993; Paxton, Ungar, \& Greene, 2011).

In the U.S., laws prohibiting "unnatural acts" (generally construed as sexual activity with the exception of vaginal intercourse between a man and a woman) have existed since colonial times (Oaks, 1978), and statutes prohibiting oral and anal sex among consenting adults were in force in many states until a 2003 Supreme Court ruling that deemed such laws unconstitutional (Lawrence v. Texas, 2003). While this ruling prohibited enforcement of antisodomy statutes in the U.S., the notions of purity as reflected in these laws remain within certain sectors of society and within the doctrine of many religions.

In this context, we would hypothesize that those strongly adhering to the purity foundation would respond more punitively than those who rank lower in sexual offending cases that involve an element of historically taboo sexual practices, including those involving homosexual contact, oral or anal sex, or sexual activity outside of marriage.

Liberty foundation. The central tenet of the liberty foundation is a strong moral belief in the right of the individual to be free from control by external agents, including freedom from unnecessary government interference in personal affairs. Placed into the context of sexual offending, one's level of adherence to this moral foundation can be reasonably hypothesized to be negatively associated with one's overall level of support for punitive policies, such as sex offender registration and notification, residence restrictions, and mandatory minimum prison sentences.

It should be noted that adherence to the liberty foundation does not imply a blindness to other moral concerns. For example, although some may adopt the extreme moral belief that adults have a right to have 'consensual' sex with children, such views are rare, since they are typically neutralized or over-ridden by one's adherence to the care foundation. However, 
adherence to the liberty foundation would likely figure prominently in one's beliefs about appropriate societal responses to sexual offenses such as violations of anti-sodomy laws, prostitution laws, or statutory rape involving consenting teenagers. Specifically, we might hypothesize that those who ascribe to strong moral beliefs tied to personal liberty would perceive prosecution of such crimes as an unnecessary government intrusion into personal affairs, and accordingly, be less likely to endorse punitive measures in such cases.

\section{Concluding Remarks}

The punitive nature of current societal discourses and public attitudes surrounding sexual offenders makes it difficult for legislators to promote more progressive schemes that may carry significant public safety benefits. Examples include such schemes that promote the community reintegration of sexual offenders (e.g., CoSA), or the delivery of early intervention strategies to those at-risk of committed offenses (e.g., the Dunkelfeld project). As long as the social consensus remains punitive in nature, these kinds of preventative and rehabilitative schemes are unlikely to be accessible to those who need help, through fear of social and judicial reprisals, and self-stigmatization (Jahnke \& Hoyer, 2013; Piché, Mathesius, Lussier, \& Schweighofer, 2016).

The analysis presented in this article indicates how the principles of moral foundations theory (MFT) might be applied to enhancing our understanding of public attitudes and societal responses to sexual offending. In articulating the connections between MFT's core premises and the social and political discourse around sexual offending, we have aimed to lay the groundwork for a new line of inquiry explaining the sources of both convergence and variability of public views and conceptualizations of sexual violence and abuse.

MFT can help us to understand the guiding principles by which people come to form judgments about sexual offenders, and accordingly about related policy responses to sexual 
offending. Establishing the factors that underpin particular attitudinal and policy-related orientations in this area is an important empirical pursuit, by contributing to our capacity to effectively communicate with the public about the most effective pathways to reducing sexual victimization in our society (Anonymous, under review). Informed by such research, effective communication methods can be developed in order to promote progressive and evidence-based policies that are supported by large proportions of the public, and that reduce the prevalence of sexual offending to make society safer. 


\section{References}

Adams, T. A., Stewart, P. A., \& Blachar, J. C. (2014). Disgust and the politics of sex: Exposure to a disgusting odorant increases politically conservative views on sex and decreases support for gay marriage. PlosONE. doi: 10.1371/journal.pone.0095572.

Amelung, T., Kuhle, L. F., Konrad, A., Pauls, A., \& Beier, K. M. (2012). Androgen deprivation therapy of self-identifying, help-seeking pedophiles in the Dunkelfeld. International Journal of Law and Psychiatry, 35, 176-184. doi: 10.1016/j.ijlp.2012.02.005.

Anonymous (under review) - information masked for peer-review.

Bastian, B., Denson, T. F., \& Haslam, N. (2013). The roles of dehumanization and moral outrage in retributive justice. Plos ONE, 8, e61842. doi:10.1371/journal.pone.0061842.

Beier, K. M., Ahlers, C. J., Döcker, D., Neutze, J., Mundt, I. A., Hupp, E., \& Schäfer, G. A. (2009). Can pedophiles be reached for primary prevention of child sexual abuse? First results of the Berlin Project Prevention Dunkelfeld (PPD). The Journal of Forensic Psychiatry \& Psychology, 20, 851-867. doi: 10.1080/14789940903174188.

Beier, K. M., Grundmann, D., Kuhle L. F., Scherner, G., Konrad, A., \& Amelung, T. (2015). The German Dunkelfeld project: A pilot study to prevent child sexual abuse and the use of child abusive images. Journal of Sexual Medicine, 12, 529-542. doi: 10.1111/jsm.12785.

Beier, K. M., Özdemir, U. C., Schlinzig, E., Groll, A., \& Hellenschmidt, T. (2016). “Just dreaming of them": The Berlin Project for Primary Prevention of Child Sexual Abuse by Juveniles (PPJ). Child Abuse \& Neglect, 52, 1-10. doi: 10.1016/j.chiabu.2015.12.009.

Boerner, D. (1992). Confronting violence: In the act and in the word. University of Puget Sound Law Review, 15, 252-577. 
Bonnar-Kidd, K. K. (2010). Sexual offender laws and prevention of sexual violence and recidivism. American Journal of Public Health, 100, 412-419. doi: 10.2105/AJPH.2008.153254.

Brown, S., Deakin, J., \& Spencer, J. (2008). What people think about the management of sex offenders in the community. The Howard Journal of Criminal Justice, 47, 259 - 274. doi: 10.1111/j.1468-2311.2008.00519.x.

Brownmiller, S. (1975). Against our will: Men, women, and rape. New York, NY: Ballantine Books.

Craun, S. W., \& Theriot, M. T. (2009). Misperceptions of sex offender perpetration:

Considering the impact of sex offender registration. Journal of Interpersonal Violence, 24, 2057-2072. doi: 10.1177/0886260508327706.

Dweck, C. S., Chiu, C., \& Hong, Y.-Y. (1995). Implicit theories and their role in judgments and reactions: A world from two perspectives. Psychological Inquiry, 6, 267-285. doi: 10.1207/s15327965pli0604_1.

Galeste, M., Fradella, H., \& Vogel, B. (2012). Sex offender myths in print media: Separating fact from fiction in U.S. newspapers. Western Criminology Review, 13, 4-24.

Giner-Sorolla, R., \& Russell, P. S. (2009). Anger, disgust and sexual crimes. In M. Horvath and J. Brown (Eds.), Rape: Challenging contemporary thinking (pp. 46-73). Cullompton, UK: Willan Publishing.

Göbbels, S., Ward, T., \& Willis, G. W. (2012). An integrative theory of desistance from sex offending. Aggression and Violent Behavior, 17, 453-462. doi: 10.1016/j.avb.2012.06.003.

Graham, J., Haidt, J., \& Nosek, B. A. (2009). Liberals and conservatives rely on different sets of moral foundations. Journal of Personality and Social Psychology, 96, 1029-1046. doi: 10.1037/a0015141. 
Gray, K., \& Keeney, J. E. (2015). Impure or just weird? Scenario sampling bias raises questions about the foundations of morality. Social Psychology and Personality Science, 6, 859-868. doi: 10.1177/1948550615592241.

Haidt, J. (2008). The moral roots of liberals and conservatives. Retrieved from https://www.ted.com/talks/jonathan_haidt_on_the_moral_mind?language=en.

Haidt, J. (2012). The righteous mind: How good people are divided by politics and religion. London, UK: Penguin.

Haidt, J., \& Graham, J. (2007). When morality opposes justice: conservatives have moral intuitions that Liberals may not recognize. Social Justice Research, 20, 98-116. doi: 10.1007/s11211-007-0034-z.

Haidt, J., \& Joseph, C. (2004). Intuitive ethics: How innately preparely intuitions generate culturally variable virtues. Daedalus, 133, 55 - 66. doi: 10.1162/0011526042365555.

Haidt, J., Koller, S. H., \& Dias, M. G. (1993). Affect, culture, and morality, or is it wrong to eat your dog? Journal of Personality and Social Psychology, 65, 613 - 628. doi: 10.1037/0022-3514.65.4.613.

Harper, C. A., \& Hogue, T. E. (2014). A prototype-willingness model of sexual crime discourse in England and Wales. The Howard Journal of Criminal Justice, 53, 511-524. doi: $10.1111 /$ hojo.12095.

Harris, A. J. (2009). Sex offenders and civil commitment: A policy review. In R. Wright (Ed.), Sex offender laws: Failed policies, new directions (pp. 219-239). New York, NY: Springer.

Harris, A. J., \& Socia, K. M. (2014). What's in a name? Evaluating the effects of the "sex offender" label on public opinions and beliefs. Sexual Abuse: A Journal of Research and Treatment. Advance online publication. doi: 10.1177/1079063214564391. 
Imhoff, R. (2015). Punitive attitudes against pedophiles or persons with sexual interest in children: Does the label matter? Archives of Sexual Behavior, 44, 35-44. doi: 10.1007/s10508-014-0439-3.

Inbar, Y., Pizarro, D., Iyer, R., \& Haidt, J. (2012). Disgust sensitivity, political conservatism, and voting. Social Psychological and Personality Science, 3, 537-544. doi: 10.1177/1948550611429024.

Iyer, R., Koleva, S., Graham, J., Ditto, P., \& Haidt, J. (2012). Understanding libertarian morality: the psychological dispositions of self-identified libertarians. PlosONE. doi: 10.1371/journal.pone.0042366.

Jahnke, S., \& Hoyer, J. (2013). Stigmatization of people with pedophilia: A blind spot in stigma research. International Journal of Sexual Health, 25, 169-184. doi: $\underline{10.1080 / 19317611.2013 .795921 .}$

Jahnke, S., Imhoff, R., \& Hoyer, J. (2015). Stigmatization of people with pedophilia: Two comparative surveys. Archives of Sexual Behavior, 44, 21-34. doi: 10.1007/s10508-0140312-4.

Jenkins, P. (1998). Moral panic: Changing concepts of the child molester in modern America. New Haven, CT: Yale University Press.

Kahneman, D. (2012). Thinking, fast and slow. London, UK: Penguin.

Katz-Schiavone, S., Levenson, J. S., \& Ackerman, A. (2008). Myths and facts about sexual violence: Public perceptions and implications for prevention. Journal of Criminal Justice and Popular Culture, 15, 291-311.

Kemshall, K., \& Wood, J. (2010). Child Sex Offender Review (CSOR) public disclosure pilots: A process evaluation. London, UK: Home Office. 
Kernsmith, P. D., Craun, S. W., \& Foster, J. (2009). Public attitudes towards sexual offenders and sex offender registration. Journal of Child Sexual Abuse, 18, 290-301. doi: $10.1080 / 10538710902901663$.

King, L. L., \& Roberts, J. J. (2015). The complexity of public attitudes toward sex crimes. Victims \& Offenders. Advance online publication. doi: 10.1080/15564886.2015.1005266.

Kitson-Boyce, R., Blagden, N., Elliott, H., Winder, B., \& Dillon, G. (2015, October). Circles of Support and Accountability: The prison model. Paper presented at the Association for the Treatment of Sexual Offenders (ATSA) Annual Conference. Le Centre Sheraton Hotel, Montreal, Canada.

Lakoff, G. (2014). The all-new “don't think of an elephant!’. White River Junction: VT: Chelsea Green Publishing Company.

Lawrence v. Texas, 539 U.S. 558 (2003)

Levenson, J. S., Brannon, Y. N., Fortney, T., \& Baker, J. (2007). Public perceptions about $\underline{\text { sex offenders and community protection policies. Analyses of Social Issues and Public }}$ Policy, 7, 137-161. doi:10.1111/j.1530-2415.2007.00119.x.

Lobanov-Rostovsky, C., \& Harris, A. (2012). State responses to federal sex offender management legislation. In B. K. Schwartz (Ed.), The sexual offender (volume 7). Kingston, NJ: Civic Research Institute.

Logan, W. (2009). Knowledge as power: Criminal registration and community notification laws in America. Stanford, CA: Stanford Law Books.

Mears, D. P., Mancini, C., Gertz, M., \& Bratton, J. (2008). Sex crimes, children, and pornography: Public views and public policy. Crime \& Delinquency, 54, 532-559. doi: $10.1177 / 0011128707308160$. 
National Center for Missing and Exploited Children (2015). Registered sex offenders in the United States and its territories per 100,000 population. Retrieved from http://www.missingkids.org/en_US/documents/Sex_Offenders_Map.pdf.

Oaks, R. F. (1974). "Things fearful to name": Sodomy and buggery in seventeenth-century New England. Journal of Social History, 12, 268 - 281. doi: 10.1353/jsh/12.2.268.

Office for National Statistics (2015). Crime statistics, focus on violent crime and sexual offences, 2013/14. Retrieved from http://www.ons.gov.uk/ons/rel/crime-stats/crimestatistics/focus-on-violent-crime-and-sexual-offences--2013-14/index.html.

Olver, M., E., \& Barlow, A. A. (2010). Public attitudes toward sex offenders and their relationship to personality traits and demographic characteristics. Behavioral Sciences and the Law, 28, 832-849. doi: 10.1002/bsl.959.

Paxton, J. M., Ungar, L., \& Greene, J. D. (2011). Reflection and reasoning in moral judgment. Cognitive Science, 36, 163-177. doi: 10.1111/j.1551-6709.2011.01210.x.

Piché, L, Mathesius, J., Lussier, P. \& Schweighofer, A. (2016). Preventative services for sexual offenders. Sexual Abuse: A Journal of Research and Treatment. Advance online publication. doi: 10.1177/1079063216630749.

Salerno, J. M., Najdowski, C. J., Stevenson, M. C., Wiley, T. R., Bottoms, B. L., Vaca, R., \& Pimentel, P. S. (2010). Psychological mechanisms underlying support for juvenile sex offender registry laws: Prototypes, moral outrage, and perceived threat. Behavioral Sciences \& the Law, 28, 58-83. doi: 10.1002/bsl.921.

Sample, L., \& Bray, T. (2006). Are sex offenders different? An examination of rearrest patterns. Criminal Justice Policy Review, 17, 83-102. doi: 10.1177/0887403405282916.

Skitka, L. J., Mullen, E., Griffin, T., Hutchinson, S., \& Chamberlin, B. (2002). Dispositions, scripts, or motivated cognition? Understanding ideological differences in explanations for 
social problems. Journal of Personality and Social Psychology, 83, 470-487. doi: 10.1037//0022-3514.83.2.470.

Sternberg, R. J. (1985). Implicit theories of intelligence, creativity, and wisdom. Journal of Personality and Social Psychology, 49, 607-627. doi: 10.1037/0022-3514.49.3.607

Sutherland, E. H. (1950). The sexual psychopath laws. Journal of Criminal Law and Criminology, 40, 543-554.

Truman, J. L., \& Langton, L. (2015). Criminal victimization, 2014. Washington, DC: U.S. Bureau of Justice Statistics.

Vess, J. (2009). Fear and loathing in public policy: Ethical issues in laws for sex offenders. Aggression and Violent Behavior, 14, 264-272. doi: 10.1177/1079063210382045.

Willis, G. M., Levenson, J. S., \& Ward, T. (2010). Desistance and attitudes towards sex offenders: facilitation or hindrance? Journal of Family Violence, 25, 545-556. doi: 10.1007/s10896-010-9314-8.

Wilson, R. J., Cortoni, F., \& McWhinnie, A. J. (2009). Circles of support \& accountability: A Canadian national replication of outcome findings. Sexual Abuse: A Journal of Research and Treatment, 21, 412-430. doi: 10.1177/1079063209347724. 